\title{
Convergent evolution inspired serrated structure for improving efficiency of soil imprinting and its mechanism investigation
}

\author{
Zhihong Zhang ${ }^{1,2^{*}}$, Ying $\mathrm{Li}^{1}$, J in Tong ${ }^{3}$, Stephen Carr ${ }^{4}$ \\ (1. College of Agriculture and Food, Kunming University of Science and Technology, Kunming 650500, China; \\ 2. United States Department of Agriculture, Agricultural Research Service, 1680 Madison Ave., Wooster, Ohio 44691, USA; \\ 3. The Key Laboratory of Bionic Engineering, Jilin University, Changchun 130025, China; \\ 4. International Soil and Water Renewables, LLC, Salem, Indiana 47167, USA)
}

\begin{abstract}
Remarkable geometrical similarities are found in digging claws of soil burrowing animals, in spite of the fact that they evolved independently. Based on convergent evolution theory, this study innovatively proposed a bionic engineering perspective that focuses on general and analogous geometrical characteristics of soil animals. It was observed that soil animals with powerful burrowing ability have analogous serrated structures on their digging claws. Taking soil imprinting toothed wheel as the research object, the hypothesis that special serrated structures have the potential of reducing penetrating resistance from soil and enhancing digging efficiency for soil engaging component was investigated. The convergent evolution inspired bionic serrated structures were utilized for the design of cutting edge on toothed wheel. Then, a toothed wheel that mounted with the conventional tooth and a bionic tooth were manufactured and tested in the soil bin. Results showed that special bionic serrated structure could reduce the required draft force for toothed wheel; meanwhile increase the depth and volume of prepared micro-basin. It was found that the soil-penetrating mechanism of the bionic toothed wheel behaved as saw cutting that similar to the digging behavior of soil burrowing animals. Geometry of serrated structure has the ability to maximum stress concentrations in soil, thus increased the tendency of soil material to fail. These results indicate that the convergent evolution inspired bionic approach is novel and advantageous for the design of new soil engaging implements for working quality optimization and forward resistance reduction.
\end{abstract}

Keywords: convergent evolution, bionic serrated structure, soil imprinting, soil-engaging component, bionic agricultural machinery

DOI: $10.25165 /$ j.ijabe.20191204.3638

Citation: Zhang Z H, Li Y, Tong J, Carr S. Convergent evolution inspired serrated structure for improving efficiency of soil imprinting and its mechanism investigation. Int J Agric \& Biol Eng, 2019; 12(4): 16-26.

\section{Introduction}

Soil imprinting is an efficient approach of in-situ water harvesting for farming systems ${ }^{[1]}$, it is an tillage operation that numerous geometrically ordered micro-basins (Figure 1a) are formed on the soil surface to collect and hold water in place during rainfall, and allowing it to infiltrate the soil ${ }^{[2-4]}$. Consequently, surface runoff is reduced, erosion is mitigated, and water infiltration rate is increased ${ }^{[5-8]}$. The imprinting toothed wheel is a rolling soil-engaging component that used for soil imprinting, which has series of peripheral tooth circumscribing rolling whee ${ }^{[9]}$. As shown in Figure 1b, when this device is hauled and rolled across the soil surface, soil flow around the tooth and lattice of consolidated discrete small micro-basins are created. Accordingly, the farming land is restructured and prepared to the desired form ${ }^{[2]}$. The efficiency of soil imprinting is measured by the quality of the

\section{Received date: 2018-04-16 Accepted date: 2019-06-20}

Biographies: Ying Li, Master candidate, research interest: bionic optimization for agricultural tillage tools, Email: m15704486549@163.com; Jin Tong, PhD, Professor, research interests: agricultural engineering bionics, Email: jtong@ jlu.edu.cn; Stephen Carr, CEO, Agricultural Engineer, research interests: soil imprinting techniques, Email: cstephencarr123@gmail.com.

*Corresponding author: Zhihong Zhang, PhD, Associate Professor, research interests: bioinspired intelligent agricultural machinery. College of Agriculture and Food, Kunming University of Science and Technology, No.727 South Jingming Rd., Chenggong District, Kunming 650500, China. Tel: +86 -15812111255, Email: zzh_0822@hotmail.com. prepared micro-basin, as well as the toothed wheel forward resistance against the soil. On the one hand, to ensure applicability, workability, and effectiveness of soil imprinting, micro-basins shape and capacity should be adapted to secure the satisfactory volume to achieve a superior run-off collecting performance ${ }^{[10]}$. On the other hand, for sloping farmland in hilly and mountainous areas, where soil imprinting is in urgent need, sizes of widely used tractors are usually small and have limited horse power. Thus, application of soil imprinting is restricted. To solve these problems, effective drug force reduction technique for toothed wheel should be researched.

Improve the shape design of soil engaging tool is one of the effective methods for reducing operating resistance and increasing working quality ${ }^{[11]}$. Since the procedure of soil imprinting by a rotary toothed wheel involves soil compression and shearing at the tooth cutting edge, hence, the shape of the tooth could significantly affect the performance of soil penetrating and the profile of the micro-basin, in turn, affect the quality of soil imprinting. Therefore, a toothed wheel with novel geometries should be investigated, and attempts should be made to improve operating efficiency of soil imprinting.

When pressed with an engineering problem in agriculture, engineers could find infinite wisdoms and inspirations from the natural world ${ }^{[12]}$. The differing environmental challenges faced by various soil burrowing animals have led to a considerable geometrical diversity of their evolved claws, most of which are distinguished by an impressive digging efficiency. Therefore, soil 
engaging tools designed based on geometrical structures of soil burrowing animals were found to have the distinguished performance and low forward resistance against soil. Also, It has been proved that the bionic designs imitating the geometrical features of soil animals' digging organs had remarkable effects on improving the performance of soil-engaging tools ${ }^{[13-16]}$.

Conventionally, in the research field of agricultural engineering bionics, the soil engaging tools optimization usually focus on individual characteristics of soil burrowing animals. That is, transfer geometrical structural characteristic from a single and specific soil burrowing animals' digging limbs to agricultural tools ${ }^{[17-19]}$. Yet, the exploration of geometrical shapes of soil burrowing animals' claw represents almost an unlimited task in view of nature's endless biodiversity. However, fresh lessons can also be generated by re - examining already known systems, particularly with regard to the notion of convergent evolution in nature ${ }^{[20]}$. Therefore, during the long-term evolutionary process, similar solutions arise among different animal species, signifying some degree of convergent evolution. Hence, convergent evolution provides a novel clue to the properties of soil burrowing animals that are critical for efficient digging. In evolutionary biology, convergent evolution is defined as the process whereby distantly related organisms independently evolve similar traits to adapt to similar necessities ${ }^{[21-23]}$. Thus, distantly related animals evolved similar solutions to various physical problems ${ }^{[24]}$. It has been postulated that this convergence occurs because principles of physics limit the number of good solutions that are available ${ }^{[25]}$. Structures that are the result of convergent evolution are called analogous structures ${ }^{[26,27]}$.

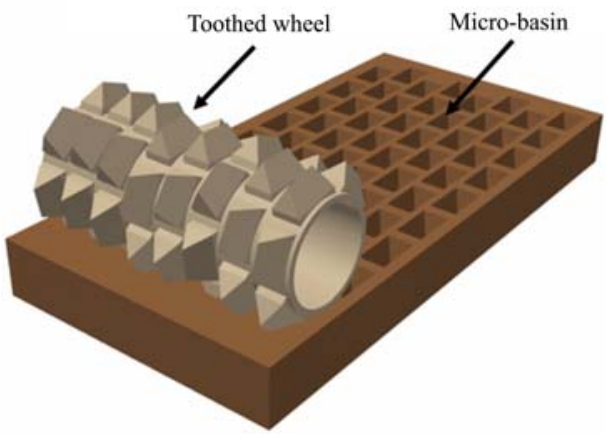

a. Schematic drawing of soil imprinting

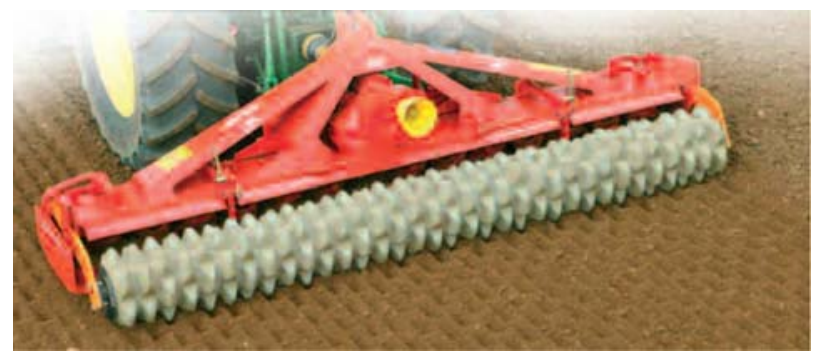

b. Operating tootheh wheel in field

Figure 1 Soil imprinting and toothed wheel

Inspired by convergent evolution, this study innovatively proposes a novel alternative approach that adopts a broader perspective: focus on analogous structures of soil animal claws that serving a similar function of soil burrowing. A bionic perspective that focuses on general and analogous geometrical characteristics of animals was innovatively proposed. The convergent properties in the context of soil imprinting toothed wheel were described, which developed to capture the special geometrical characteristics of the claws of soil burrowing animals. Based on convergent evolution, analogous structures existing in soil burrowing animals' digging claws were studied, and their essence and commonality were abstracted. Then these geometrical structures were expressed by the bionic serrated structure, used for the design of optimized cutting edge of the toothed wheel. Afterwards, toothed wheel mounted with one type of conventional tooth, three types of the bionic tooth were assembled, and traction tests in soil bin were conducted. Taking required draft force, depth, and volume of prepared micro-basin as the indexes, working efficiency, and quality of different toothed wheels were evaluated.

\section{Materials and methods}

\subsection{Geometrical structure designs of naturally evolved digging limbs}

When organisms that are not closely related evolve similar traits as they both adapt to similar environments, because there are a finite number of effective solutions to some challenges, and some of them emerge independently again and again. Convergent evolution is the process by which unrelated species evolve similar physical characteristics because they have similar lifestyles. That is to say, functionally similar features that have arisen through convergent evolution are analogous. Soil burrowing animals are the most successful members of the animal kingdom largely because of their ability to burrow and move efficiently underground through a range of harsh soil environments. Where animal groups evolved the same solutions independently, geometrical structures that are similar suggest excellent solutions to physical constraints. Lessons of convergent evolution can be utilized to guide the design of soil tillage tools.

It was inspiring to find evidence of convergent evolution in the resemblance of the digging claws of Mole rat (Scaptochirus moschatus), Mole crickets (Gryllotalpa orientalis Burmeister), Pangolin (Manis pentadactyla), and Dung beetle (Copris ochus Motschulsky). As exemplified by the resemblance among the soil burrowing animals mentioned above, remarkably similar claws with similar serrated structure have been utilized, representing long-term convergent evolution, but largely independent adaptation of organisms to their respective adaptations. From the bionic engineering perspective, several common principles underlying the designs of the largely diverse digging limbs could be extracted, as different shaped serrated structures. These soil burrowing animals are powerful diggers, able to conceal themselves at amazing speed; they have short, strong legs with daunting claws. It's worth noting that they are only distantly related, but the species within each have converged on a remarkably similar serrated structure on their digging claws. Although these animals are ranging from insecta to mammalia, and the size of geometrical features of digging claws differed form meso-scale to macro-scale, the serrated structure is the geometrical characteristic that general in essence (Figure 2). This convergence occurred because animal groups must solve the same physical problems relevant to digging through hard and compacted soil against forces such as shearing, compression and friction.

Convergent evolution arises when an adaptation has arisen independently, creating analogous structures. In contrast, divergent evolution is the accumulation of differences between groups, leading to the formation of new species. For soil burrowing animals, to scrutinize the relationship between convergent evolution and serrated structure on digging claws. Evidence of divergent evolution were demonstrated from the opposite angle, to reversely prove that serrated structures are the outcome of convergent evolution for adapting the underground 
environment.
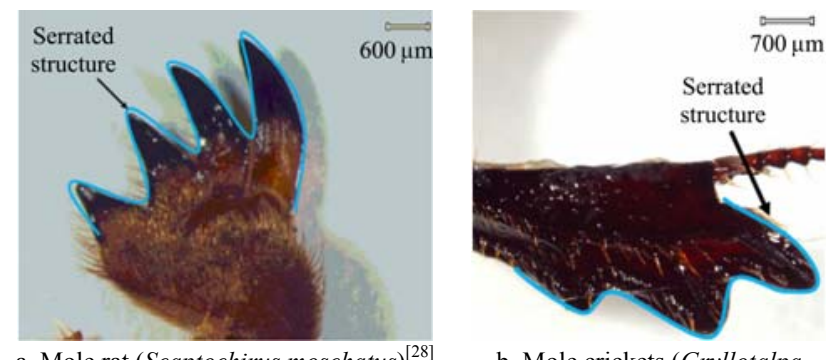

b. Mole crickets (Gryllotalpa

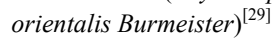

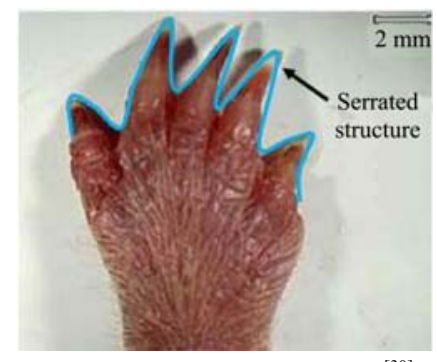

c. Pangolin (Manis pentadactyla) ${ }^{[30]}$

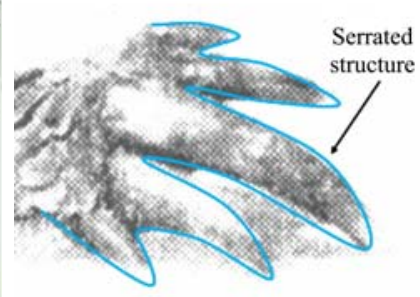

d. Dung beetle (Copris ochus Motschulsky $)^{[31]}$
Figure 2 Serrated structures existing in soil burrowing animals' forelegs

One of the insightful evidences of divergent evolution can be found between two typical members of Orthoptera: cotton grasshopper (Chondracris rosea (De Geer)) and mole cricket (Gryllotalpa brachyptera). Cotton grasshoppers are plant-eaters that live above ground, they often bask in the sun and thrive in warm sunny conditions, dwelling among cereals, vegetables, and pasture above ground. They have powerful hind legs, which enable them to escape from threats by leaping vigorously. However, these claws are more adapted for leaping rather than digging, which they do rarely and poorly ${ }^{[32]}$. Therefore, as shown in Figure 3a, the forelegs of cotton grasshoppers are smoothed and do not have serrated structure. On the contrary, mole crickets mainly feeding on roots, live almost entirely below ground. They have been adapted for underground life, digging tunnels of different kinds for the major functions, including feeding, escape from predators and raising of young. Hence, their saw-like forelimbs highly developed for burrowing, can dig themselves underground rapidly ${ }^{[33-35]}$. As shown in Figure 3b, fossorial forelimbs of a mole cricket have evident special serrated structure.

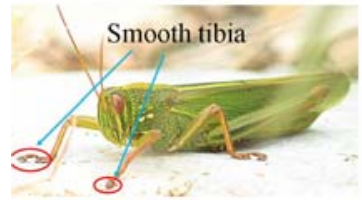

a. Locust (Chondracris rosea (De Geer))

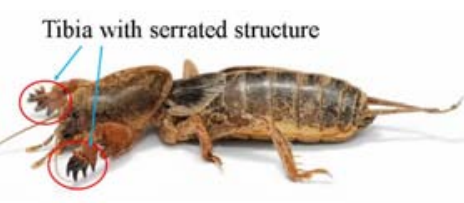

b. Mole cricket (Gryllotalpa brachyptera)
Figure 3 Two members of Orthoptera

Another intriguing evidence of divergent evolution can be found in two species of beetles. The species of goldsmith beetle (Cetonia aurata), which is commonly found sitting in flowers or meadows, feeding on petals, leaves, pollen or nectar of flowers. The forelegs of this species of beetle do not have the function of soil digging. On the contrary, for the species of dung beetle (Copris ochus Motschulsky), living surrounding is very different from goldsmith beetle. Dung beetle as a kind of soil animal has to dig and burrow in soil diligently. Therefore, the forelegs of dung beetle have strong soil burrowing ability. They can break up hard soil clods and dig into the firm soil. Two different adaptations occurred in these two species of beetles, the passive adaptation, and the active adaptation. To adapt to different living surroundings, the evolutionary strategy adopted by goldsmith beetle was a passive one, which resulted in vestigial forelegs and does not have a serrated structure on the tibia (Figure 4a). While, the evolutionary strategy adopted by dung beetle was an active one, which results in strong forelegs with serrated structures on the tibia (Figure 4b). The resistant force reduction function of dung beetles' digging organ against soil is an inevitable outcome through divergent evolution.

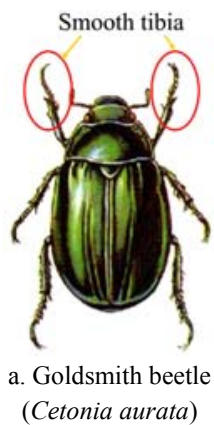

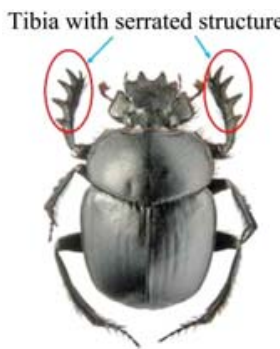

b. Dung beetle Copris ochus Motschulsky)
Figure 4 Two types of beetles

From the evidences above, it can be found that quite special in geometrical character are the claw of the soil burrowing animals. Animals that habitually burrow into the earth, the soil penetrating resistance and friction drag of moving through the ground is potentially enormous. Hence, the claws of digging animals are usually with special geometrical character, to do the work of a pickaxe in breaking the soil surface. The claws of animals that lead an almost completely subterranean life, like the Mole rat, Mole crickets, Pangolin, and Dung beetle, each short stroke of a claw must move as much earth as possible. Their claws are powerful and with special serrated structures.

\subsection{Manufacturing of conventional and bionic toothed wheel}

The digging claws of soil burrowing animals, such as Mole rat, Mole crickets, Pangolin and Dung beetle evolved independently from each other, but similar serrated structures are evolved to perform the function of soil burrowing. As shown in Figure 5, the serrated structures were chosen as a bionic prototype. Meanwhile, the bionic structure was adopted as a design approach for the design of bionic tooth.

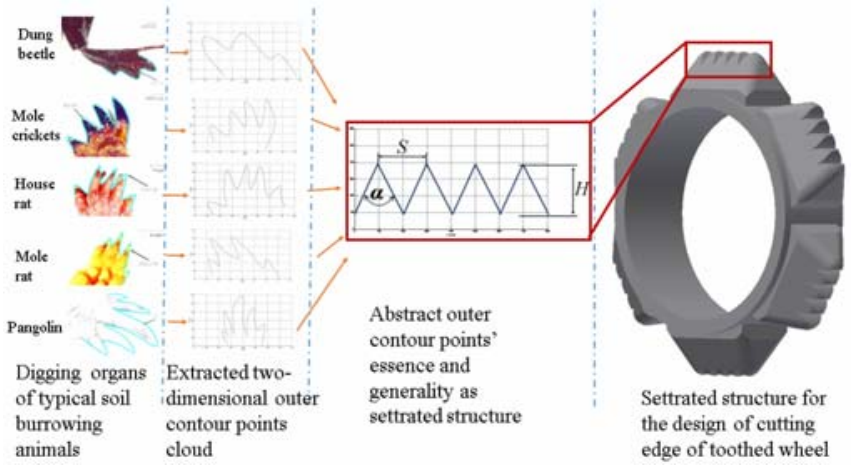

Figure 5 Flow diagram of design of bionic toothed wheel

Based on the serrated structures inspired form digging claws of soil burrowing animals, three types of the different bionic tooth and one type of conventional tooth were designed, manufactured and assembled on rolling wheel. CNC machine was used to mill the arc surface of tooth bottom that fit with rolling wheel. Then, milling machine was used to process the four-side bevel. 
Afterwards, shaping machine was used to plane serrated structures with different sizes on cutting edge of the tooth. After that, drilling machine was used to dill four screw holes for bolted connection. Eventually, six-tooth unit were fit on a rolling wheel.

The conventionally used tooth was named as a conventional tooth (CT). Tooth with bionic inspired serrated structures was named as a bionic tooth (BT). As shown in Figure 6, the CT had a smooth cutting edge without serrated structures. Bionic tooth 1 (BT1) had tiny serrated structure on cutting edge, each serrated structure element was equilateral triangle with length of $10 \mathrm{~mm}$ and 10 equilateral triangles were placed on cutting edge; bionic tooth 2
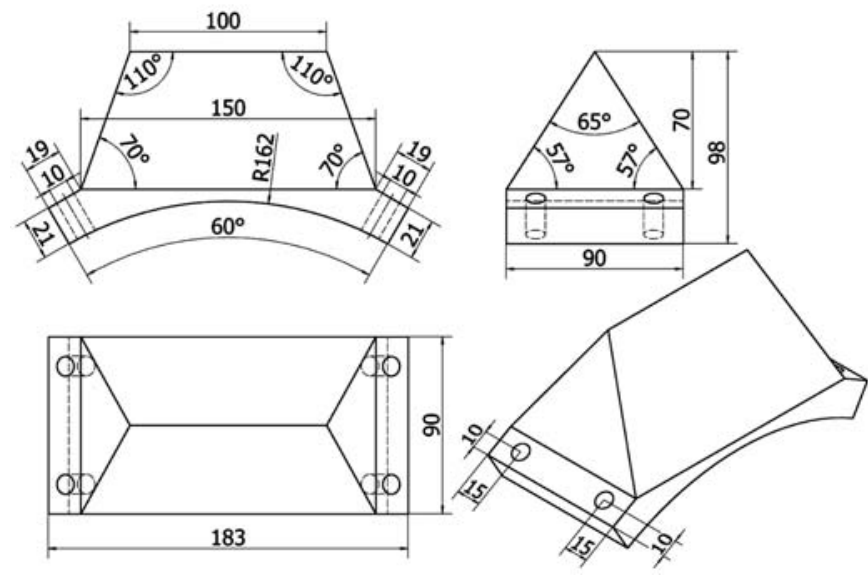

a. CT

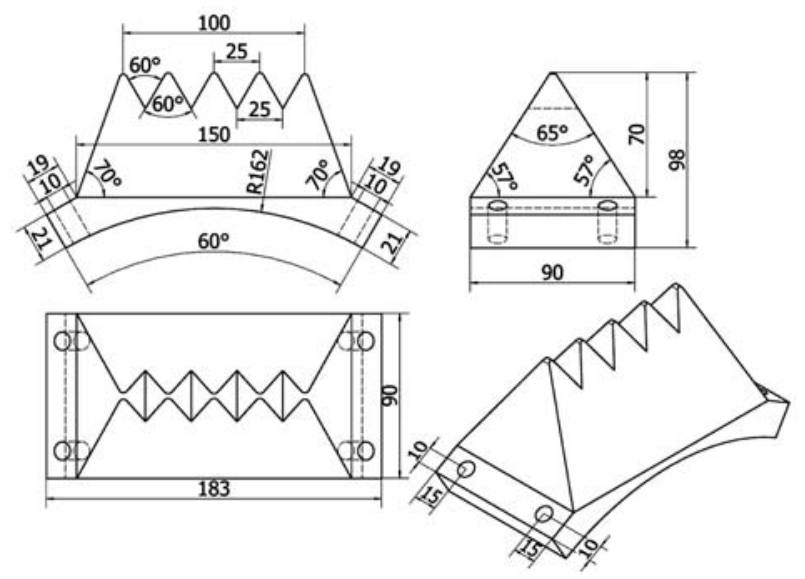

c. BT2
(BT2) had medium serrated structure on cutting edge, each serrated structure element was equilateral triangle with length of $25 \mathrm{~mm}$ and five equilateral triangles were placed on cutting edge; bionic tooth 3 (BT3) had a relatively large serrated structure on cutting edge, each serrated structure element was equilateral triangle with length of $50 \mathrm{~mm}$ and 3 equilateral triangles were placed on cutting edge.

To form micro-basins when rolling over the soil surface, six experimental teeth were mounted on a steel rotary wheel unit with $320 \mathrm{~mm}$ diameter and connected to a steel frame. Eventually, the whole unit toothed wheel was trailed behind a soil bin carriage (Figure 7).
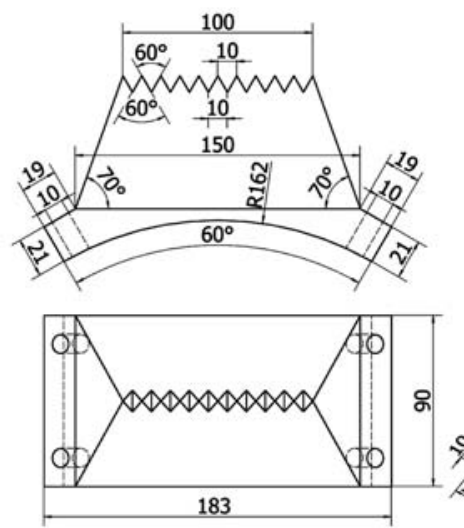

b. BT1
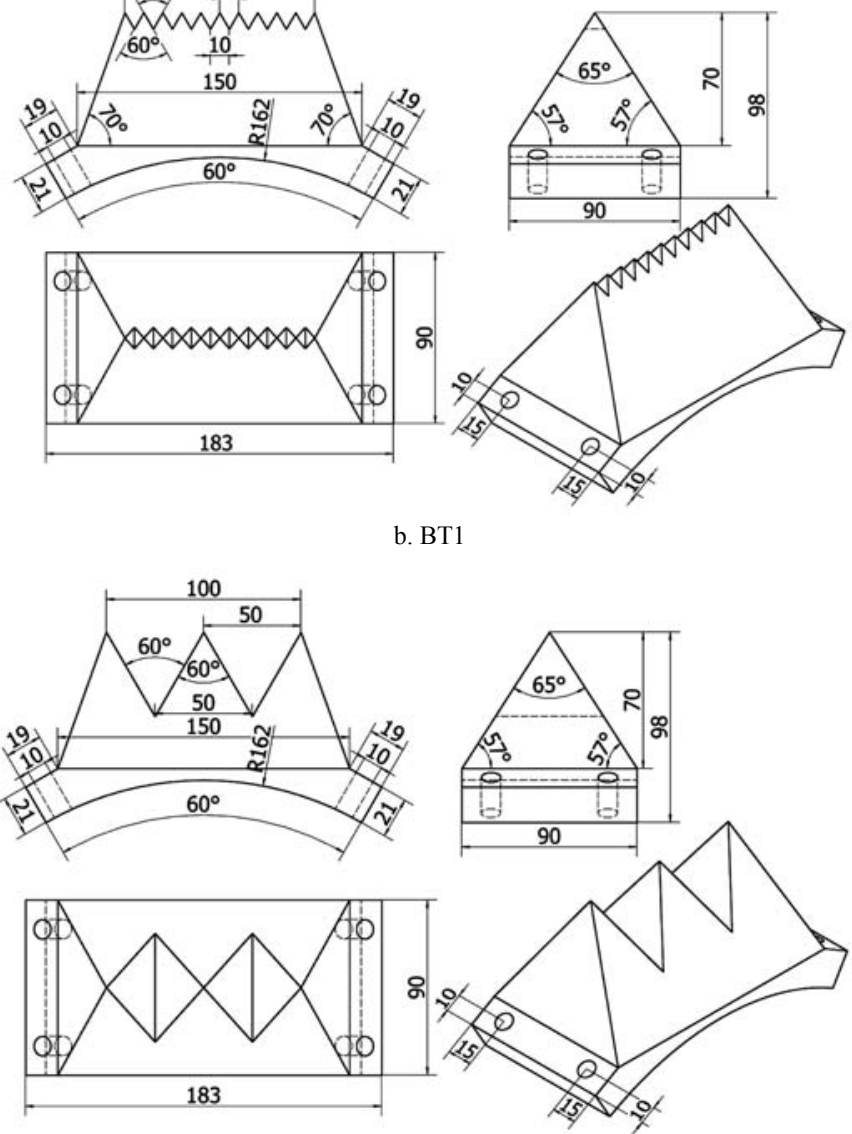

d. BT3

Figure 6 Scale drawing of different types tooth

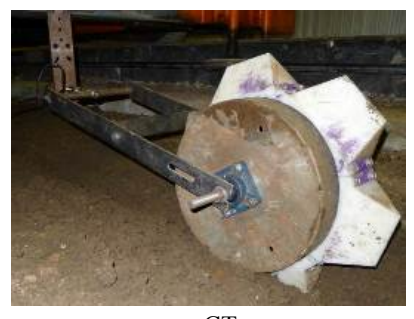

a. CT

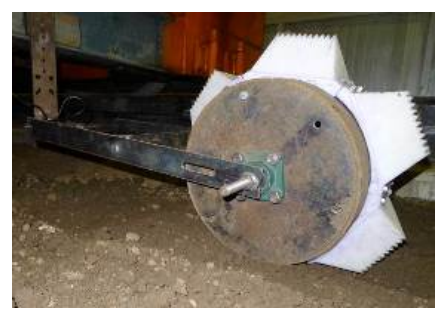

b. BT1

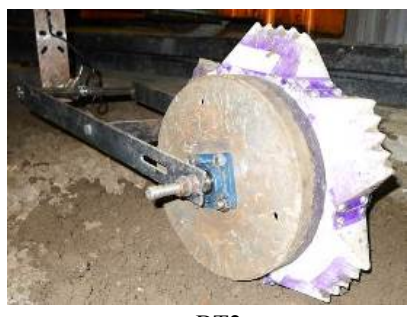

c. BT2

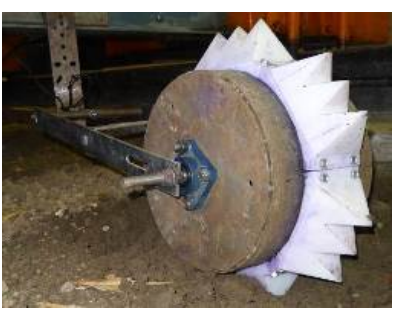

d. BT3

Figure 7 Different types of tooth assemble with rolling wheel

\subsection{Soil preparation}

This study was conducted using the indoor soil bin facility at the key laboratory of bionic engineering (Ministry of Education, China $)^{[17,36]}$. Soil bin (40 m long, $2.8 \mathrm{~m}$ wide and $1.8 \mathrm{~m}$ deep) was used to produce a repeatable soil condition for the experiment, and soil bin trolley was used to provide a constant forward travel speed. The yellow clay soil, which is typical soil of a large proportion of the maize and soybean growing regions of northeastern China, was used for this experiment. The soil preparation in each bin involved adding a pre-determined amount of water to reach a targeted moisture content of $12.34 \%$ (w/w dry basis) with an average a bulk density of $1200 \mathrm{~kg} / \mathrm{m}^{3}$ (dry basis). The soil was covered with polyethylene sheets after watering to minimize moisture loss while allowing moisture to equalize within the bin. In the following day loosening, mixing and leveling to a set height. Between each run of the experiment, the shovel was used to lose soil and scraper blade was used to level soil manually. During the tests, previously worked the soil in the bin was covered 
with polyethylene sheets to avoid soil moisture evaporation from the air. Before conducting tests on the following day, soil samples were collected from bin to monitor the bulk density and the moisture content.

\subsection{Method for data acquisition}

The data sampling was conducted over $10 \mathrm{~m}$ long stable working section of the soil bin, other $5 \mathrm{~m}$ long buffering areas at each end for soil bin trolley's deceleration and acceleration. A force sensor (LCS-S3) was set up between the toothed wheel and the front bar of the carriage. Then, the force signal acquired by force sensor was transferred to data acquisition system. Data acquisition system was shown in Figure 8, among which, signal amplifier (RW-ST01A) was used to amplify force signal, then the amplified signal was transferred to USB-powered portable measurement device (NI myDAQ, $200 \mathrm{kS} / \mathrm{s}, 16 \mathrm{bits}, \pm 10 \mathrm{~V}$ ) and measurement device was connected to portable computer through USB port, eventually, force data were collected by operation platform on portable computer developed by LabVIEW software.

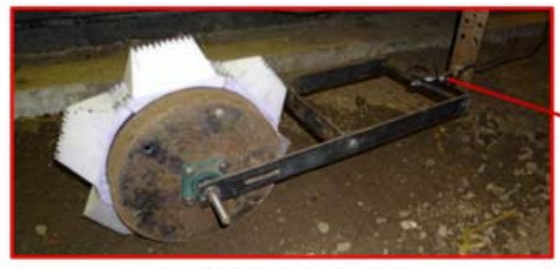

Imprinting toothed wheel

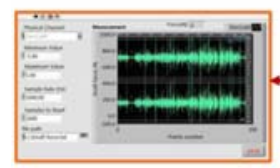

Data logging software

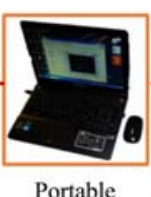

Portable

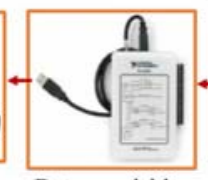

Data acquisition card
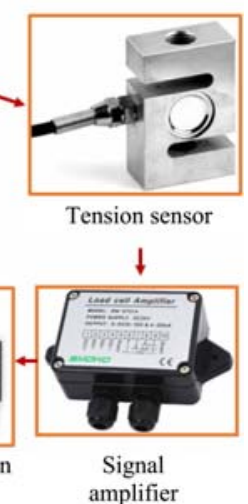

amplifier
Figure 8 Data acquisition system

As shown in Figure 9, the experiments which measure forward resistance of toothed wheel were conducted by using an electric carriage moving on rail tracks on both sides of soil bin as a source of power. The toothed wheel assembly as test unit was fitted to the test rig which traveled over a soil bin at a forward speed of $1 \mathrm{~m} / \mathrm{s}$ (typical speed of toothed wheel for operating behind a four-wheeled tractor).

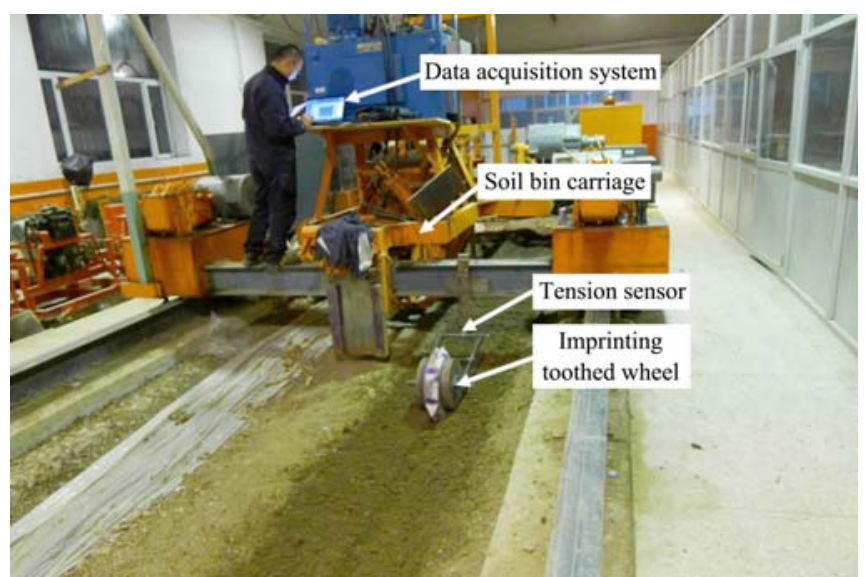

Figure 9 Soil bin test platform for toothed wheel

Toothed wheel requires an adequate implemented load to apply perpendicular to the soil surface, thus allowing the soil structure to be compressed to create imprints. Implement weight was varied by the addition of ballast. The initial un-laden weight of toothed wheel was $250 \mathrm{~N}$, to investigate effects of loads on toothed wheel working quality, weight was evenly distributed on both sides of rolling wheel shaft after weight was added, toothed wheel total weight was $300 \mathrm{~N}$ and $350 \mathrm{~N}$, respectively. At each load, full replication of five experimental runs was completed over soil bin. The collected data sets were statistically analyzed, and error bars were used to represent standard deviation.

\subsection{Method for measuring working quality}

For any given soil conditions, the amount of water harvested by a micro-basin depends on the depth of the micro-basin and its volume, both of the indexes determine reservoir capacity and influence the working quality of soil imprinting. To evaluate reservoir capacity, digital depthometer was used to measure the depth of each micro-basin and take $1 \mathrm{~mm}$ of accuracy. Meanwhile, the volume of each micro-basin was determined by lining it with thin plastic film $(75 \mu \mathrm{m})$ and filling it with water to the surface, then the difference reading from the measuring cylinder was calculated, and the volume of micro-basin was determined (Figure 10). For each repetition, 15 micro-basins were selected randomly, the collected data sets were statistically analyzed, and error bars were used to represent standard deviation.

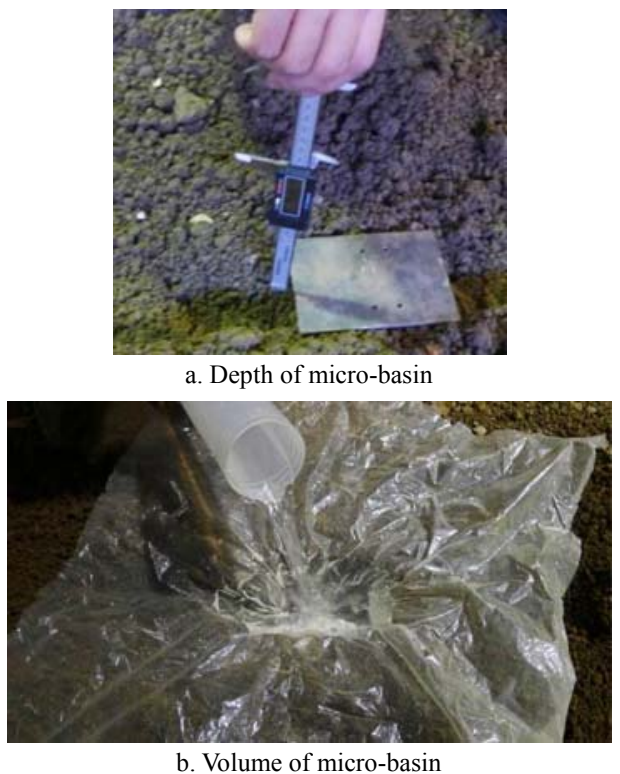

Figure 10 Methods for measuring of micro-basins geometrical characteristics

\subsection{Development of FEM dynamic model to investigate} interaction mechanism between soil and toothed wheel

To study and compare the behavior of soil and toothed wheel interface, stress results were achieved analytically by FEM (Finite Element Method). Recent developments in computer technology have led to more applications of FEM to soil-tillage tool interactions ${ }^{[37,38]}$. FEM is efficient at analyzing complex engineering problems, especially for dynamic systems with significant deformation, and it has been used by many researchers to analyze problems related to soil mechanics ${ }^{[39,40]}$.

In this study, finite code ABAQUS was used, a 3D finite element analysis of soil and toothed wheel interaction was carried out to investigate the behavior of the soil and toothed wheel interface. A calibrated finite element model ${ }^{[41]}$ was established and provided realistic estimates of the stress at the contact interface between soil and toothed wheel thereby predicts soil stress. As a compromise to cut down solution times, analyses were carried out through $1000 \mathrm{~mm}$ center movement in the horizontal plane along the X-axis direction within $1 \mathrm{~s}$. Using an Intel i7-4790K 4GHZ processor workstation $\mathrm{PC}$ with $24 \mathrm{~GB}$ of memory, full analysis jobs were created and submitted to the solver. 


\section{Results and discussion}

\subsection{Effects of bionic serrated structures on forward resistance}

At the operating load of $250 \mathrm{~N}$, results showed that the toothed wheel with BT1, BT2, and BT3 reduced the forward resistance by $2.41 \%, 6.52 \%$, and $7.82 \%$, respectively, as compared with CT. Among bionic tooth, the lowest forward resistance was recorded by the toothed wheel with BT3, forward resistance of BT2 is slightly higher than BT3, while the highest forward resistance was recorded by BT1.

At the operating load of $300 \mathrm{~N}$, results showed that the toothed wheel with BT1 increased the forward resistance by $1.25 \%$ as compared with CT. However, a toothed wheel with BT2 and BT3 showed $3.04 \%$ and $4.20 \%$ reduction in forward resistance respectively as compared with $\mathrm{CT}$. Among bionic tooth, also, the lowest forward resistance was recorded by the toothed wheel with BT3, forward resistance of BT2 is slightly higher than BT3, while the highest forward resistance was recorded by BT1.

At the operating load of $350 \mathrm{~N}$, results showed that the toothed wheel with BT1 and BT2 reduced the forward resistance by $1.13 \%$ and $0.95 \%$ respectively, as compared with CT. Yet, a toothed wheel with BT2 showed $6.06 \%$ reduction in forward resistance as compared with CT. Among bionic tooth, the highest forward resistance was recorded by the toothed wheel with $\mathrm{BT} 1$, while the lowest forward resistance was recorded by BT2.

From the Figure 11, it is noticeable that the forward resistance of toothed wheel mounted with different types of tooth increases as the implemented load increase. When operating at minor load, the difference of forward resistance between toothed wheel with conventional tooth and the bionic tooth was subtle. As the load increase to a certain extent, working resistance of toothed wheel with BT2 was apparently lower than those of other types of the tooth.

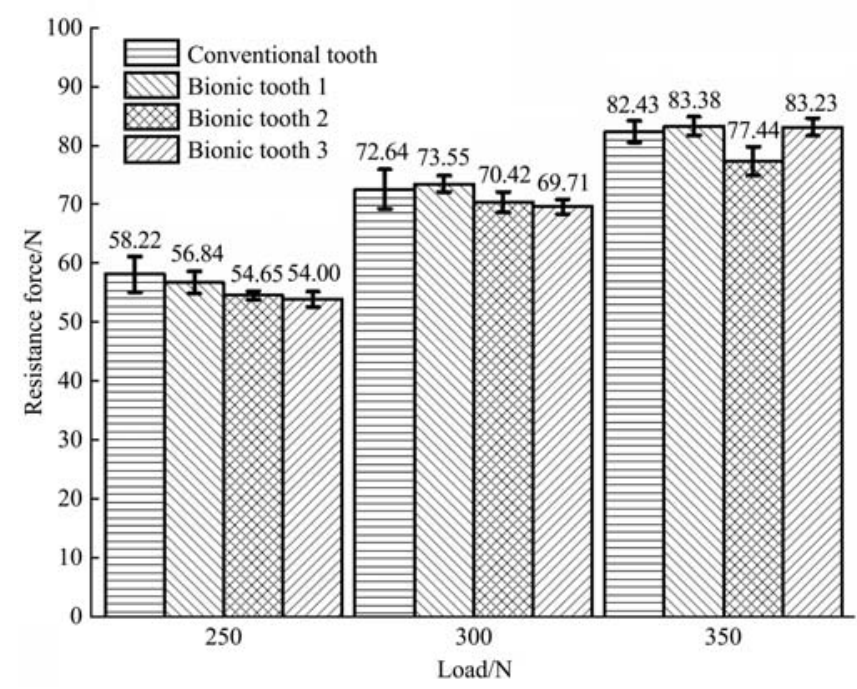

Figure 11 Test result of forward resistance for toothed wheel with different teeth

3.2 Effects of bionic serrated structures on depth of micro-basin

At the operating load of $250 \mathrm{~N}$, results showed that the toothed wheel with BT1, BT2 and BT3 increased the depth of micro-basin by $3.90 \%, 5.01 \%$, and $4.18 \%$ respectively, as compared with CT. Among bionic tooth, the lowest depth of micro-basin was recorded by the toothed wheel with BT1, while the highest depth of micro-basin was recorded by the toothed wheel with BT2.

At the operating load of $300 \mathrm{~N}$, results showed that the toothed wheel with BT1, BT2 and BT3 increased the depth of micro-basin by $4.16 \%, 13.25 \%$, and $11.17 \%$ respectively, as compared with CT. Among bionic tooth, the lowest depth of micro-basin was recorded by the toothed wheel with BT1, while the highest depth of micro-basin was recorded by BT2.

At the operating load of $350 \mathrm{~N}$, results showed that the toothed wheel with BT1 decreased the depth of micro-basin by $0.24 \%$ as compared with a toothed wheel with CT. While toothed wheel with BT2 and BT3 increased the depth of micro-basin by $7.31 \%$ and $4.95 \%$ respectively, as compared with CT. Among bionic tooth, the lowest depth of micro-basin was recorded by the toothed wheel with BT1, while the highest depth of micro-basin was recorded by BT2.

Similarly, from the Figure 12, it is noticeable that the depth of micro-basin created by toothed wheel mounted with different types of tooth increased as the implemented load increase. When operating at minor load, the difference of working resistance between toothed wheel with conventional tooth and the bionic tooth was not obvious. As the load increase to a certain extent, depth of micro-basin created by the toothed wheel with BT2 was apparently higher than other types of toothed wheel.

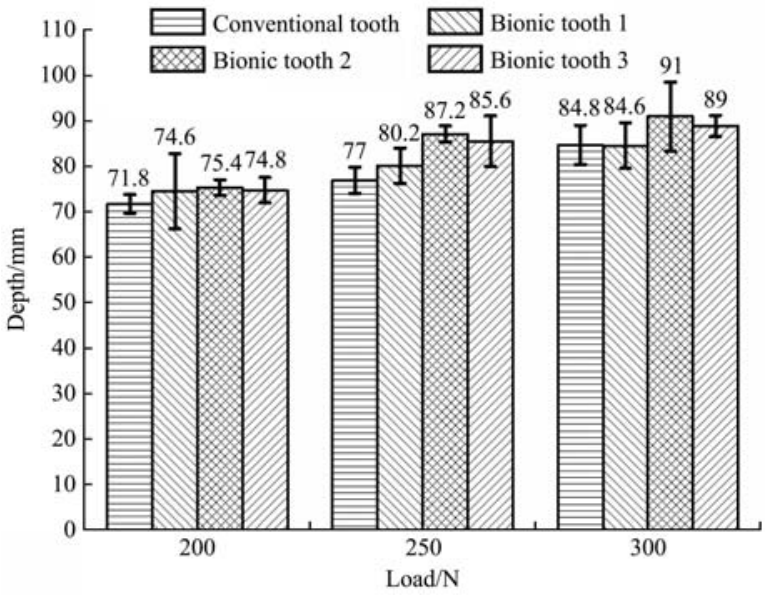

Figure 12 Test result depth of micro-basin created by toothed wheel with different tooth

3.3 Effects of bionic serrated structures on volume of micro-basin

At the operating load of $250 \mathrm{~N}$, results showed that the toothed wheel with BT1 and BT2 increased the volume of micro-basin by $31.91 \%$ and $37.59 \%$ respectively, as compared with CT. While toothed wheel with BT3 decreased the volume of micro-basin by $7.80 \%$ as compared with CT. Among bionic tooth, the lowest volume of micro-basin was recorded by the toothed wheel with BT3, while the highest volume of micro-basin was recorded by BT2.

At the operating load of $300 \mathrm{~N}$, results showed that the toothed wheel with BT1 and BT2 increased the volume of micro-basin by $16.17 \%$ and $23.35 \%$ respectively, as compared with CT. While toothed wheel with BT3 decreased the volume of micro-basin by $5.39 \%$ as compared with CT. Similarly, among bionic tooth, the lowest volume of micro-basin was recorded by the toothed wheel with BT3, while the highest volume of micro-basin was recorded by BT2.

At the operating load of $350 \mathrm{~N}$, results showed that the toothed wheel with BT1 and BT2 increased the volume of micro-basin by $19.77 \%$ and $20.07 \%$ respectively, as compared with CT. While toothed wheel with BT3 decreased the volume of micro-basin by $1.16 \%$ as compared with CT. Similarly, among bionic tooth, the lowest volume of micro-basin was recorded by the toothed wheel with BT3, while the highest volume of micro-basin was recorded by BT2. 
From Figure 13, it is noticeable that volume of micro-basin created by toothed wheel mounted with different types of tooth increase as the implemented load increase. Even when operating at small load, the difference of working resistance between toothed wheel with conventional tooth and the bionic tooth was noticeable. At different loads, the volume of micro-basin created by the toothed wheel with BT2 exceeded other types of the tooth, the volume of micro-basin created by the toothed wheel with BT1 slightly lower than BT2, while BT3 showed the lowest volume of micro-basin at different loads, even lower than CT.

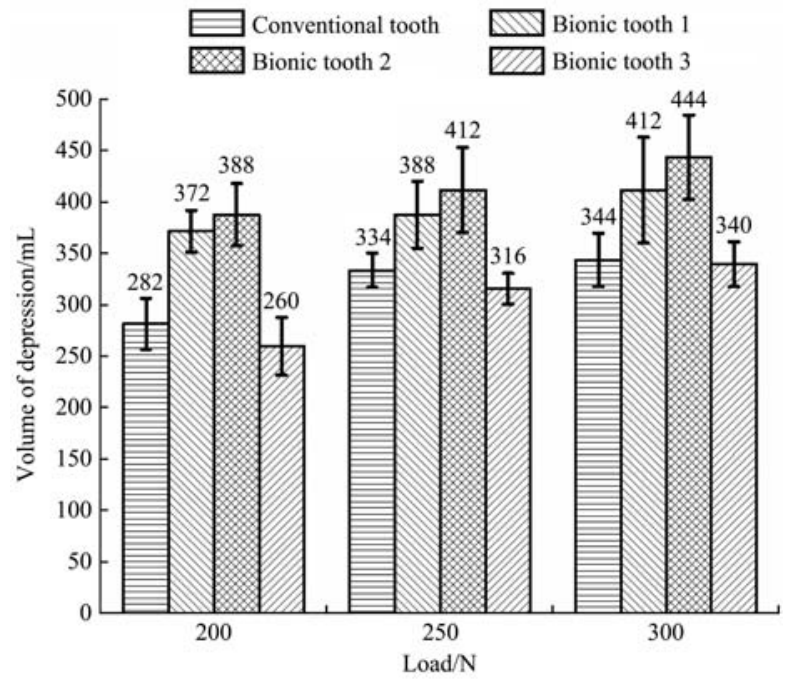

Figure 13 Test result volume of micro-basin created by toothed wheel with different tooth

\subsection{Investigating mechanism of bionic toothed wheel working efficiency improvement from the perspective of geometrical features}

To investigate the mechanism of bionic toothed wheel resistant reduction and working quality improvement, tooth surface area and volume at different section were calculated. When tooth penetrating into the soil, cutting edge of the tooth was used to penetrate into the soil and will affect working resistance, while the main body of the tooth was used to push soil aside and will affect the volume of micro-basin. For the convenience of calculation, the part of the tooth below $Z_{1}$ was designated as cutting edge, while the part of tooth blow $Z_{2}$ was named as main body (Figure 14).

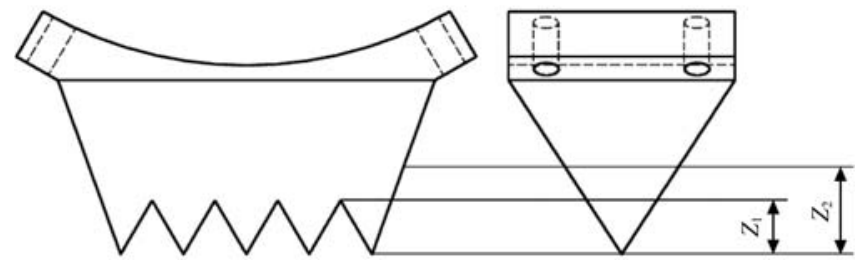

Figure 14 Diagrammatic drawing of tooth

The surface area and volume of different types of the toothed wheel at different parts of cutting edge and main body were calculated, the results were shown in Figure 15 and 16. Among different types of the tooth, when working at minor load, the cutting edge of BT3 had the smaller surface area, hence when interacting with soil, lower adhesion force was generated. Furthermore, BT3 had the smallest volume at cutting edge, therefore had lower penetration force when digging into the soil. Consequently, a toothed wheel with BT3 can operate with lower forward resistance at minor load. However, as the load increased, all toothed wheel penetrates into soil deeper, the main body surface area and volume tend to be similar. Hence the anti-adhesion advantage of BT3 was no longer apparent. Therefore, forward resistance of BT3 increased. Furthermore, the volume of the BT3 main body was much lower than other types of the tooth; this disadvantageous feature determined that micro-basins created by BT3 have lower volume. Also, the main body of BT3 had more surface area at greater depth; this feature increased adhesion force. As a result, the forward resistance was increased.

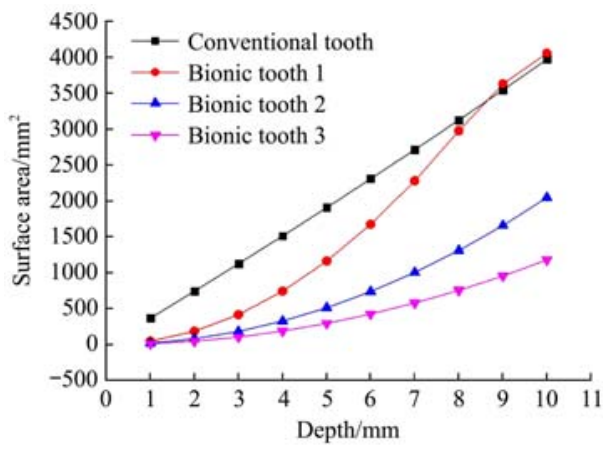

a. Surface area

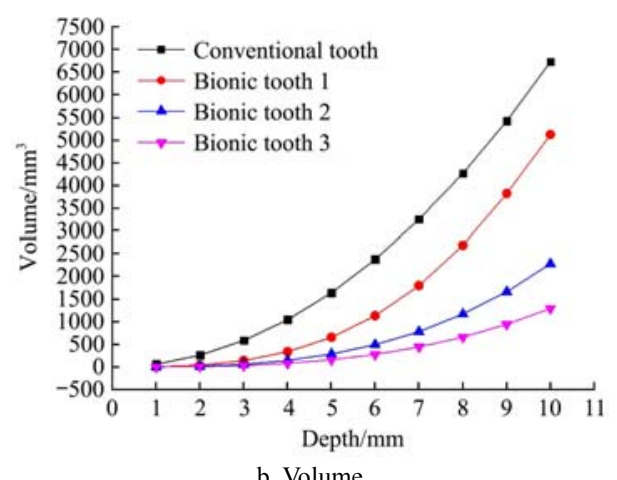

b. Volume

Figure 15 Geometrical features of tooth cuttin g edge

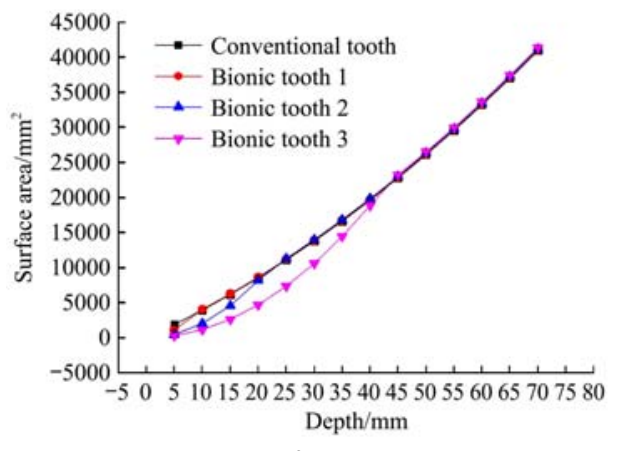

a. Surface area

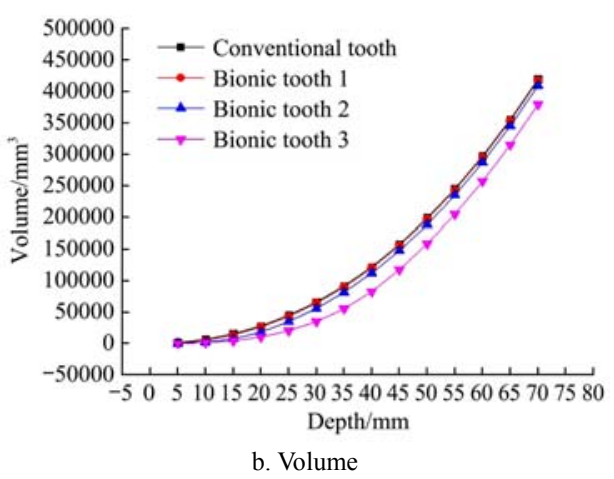

Figure 16 Geometrical features of main tooth body

Similarly, the tip of cutting edge of BT1 had a lower surface area, yet as the depth increased, the surface area obviously increased, when the depth increased to $8 \mathrm{~mm}$, the surface area of BT1 on cutting edge even larger than CT. Hence the adhesion phenomenon of a toothed wheel with BT1 was more severe than 
other types of the tooth.

It is worth noting that BT2 reached a balance between surface area and main body volume. On the one hand, BT2 had lower surface area and volume on cutting edge, hence when BT2 interact with soil, it had lower adhesion force and penetrating resistance. Moreover, main body volume of BT2 was not reduced. As a result, the volume of micro-basin was not evidently limited.

This phenomenon above can also be seen from Figure 17, different types of the tooth produced different micro-basin shapes. The bottom of micro-basin created by CT was a smooth straight line (vertex EF); the bottom of micro-basin created by BT1 has fine waved structure (vertex EFGH); the bottom of micro-basin created by BT2 was coarse serrated structure (vertex EFGH); the bottom of micro-basin created by BT3 was inverted rectangular pyramid structure (vertex EFG). The pyramid structure severely compromised reservoir capacity of micro-basin. Hence micro-basin created by BT3 had limited volume compared to other types of the tooth.

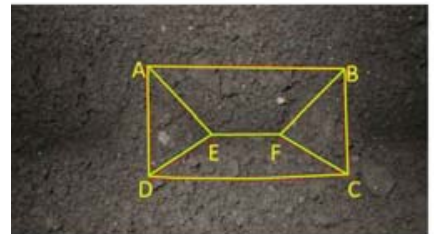

a. CT

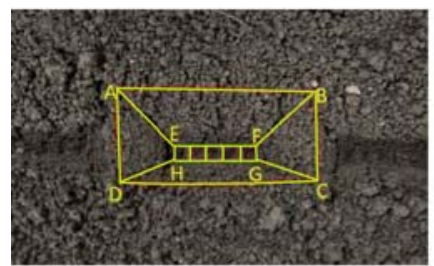

c. BT2

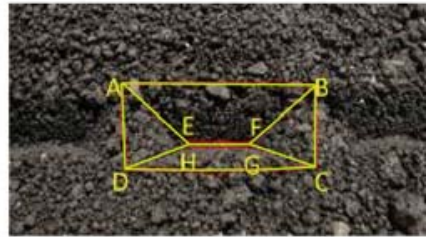

b. BT1

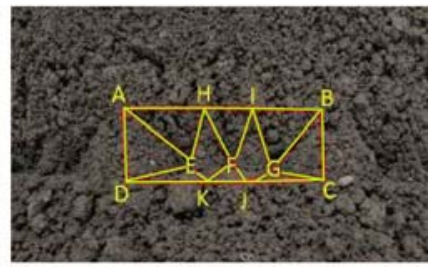

d. BT3
Figure 17 Micro-basin shapes produced by different types of tooth

As far as forward resistance be concerned, another explanation can be given from the perspective of air pressure existing between soil and tillage tool. It has been proved that the negative air pressure existing within the closed structural units plays an important role in soil adhesion ${ }^{[42,43]}$. The reason that the reduction of soil adhesion on the tooth with serrated structure is that the contacting area of the soil-tooth interface was decreased, meanwhile vent openings on the interface connecting it to surrounding environment reduced the opportunity of the negative air pressure formation. Accordingly, the pressure in the direction of motion on the soil and toothed wheel interfaces were decreased. The bionic serrated structure on the toothed wheel may reduce the contact area of soil-tooth interfaces, hence resulting in lower soil adhesion, and consequently, lower forward resistance.

3.5 Investigating mechanism of bionic toothed wheel working efficiency improvement from the perspective of FEM

For the FEM model of interaction between soil and CT, solution time was about $60 \mathrm{~h}$. Yet, due to the relative complexity geometry of the bionic toothed wheel, FEM model solution time reached to $580 \mathrm{~h}$. Both of the analysis was accomplished satisfactorily without element distortion or interruption.

As shown from Figures 18-21, soil stresses on toothed wheel and soil interface were predicted, contours on deformed shape were plotted, the evolution of the von Mises stress spectrum field for the BT2 and CT roll over soil surface were outputted. Although the interaction between soil and the toothed wheel is a continuous procedure, in this study, four working phases were defined manually based on unique working characteristics: stamping (0.988 s), pressing (1.118 s), compacting (1.196 s) and rolling (1.248 s), respectively.

An object is most robust when force is evenly distributed over its area. However, geometric discontinuities cause an object to experience a local increase in the intensity of a stress field. Therefore object cease to function satisfactorily because they break before either excessive elastic deflection or general yielding occurs $^{[44,45]}$. Examples of shapes that cause these concentrations are cracks, sharp corners, holes, and changes in the cross-sectional area of the object ${ }^{[46]}$. The sharp corners at the serrated structure of BT2 can cause geometric discontinuities in soil material, these discontinuities caused sudden increases in the stress at points near the stress raisers, has resulted in a localized increase in stress, such stress concentration within the soil causing it to fail more easily. Hence, the geometry of serrated structure can maximize stress concentrations in soil, thus increased the tendency of soil material to fail. Moreover, nonuniformity of stress may occur because of geometric changes such as notches in the cross-section of a specimen. This nonuniformity in stress distribution may result in maximum stress in a section that is considerably larger than the average stress. The term of stress gradient is used to indicate the rate of increase of stress as a stress riser is approached. Such stress gradient may influence the damaging effect of the peak value of the stress. As shown in stress spectrum field from Figures $18-21$, in the neighborhood of soil and toothed wheel interface, the calculated stress gradient of BT2 is steeper in the region of stress concentration than $\mathrm{CT}$, so stress cause by BT2 serrated structure showed abrupt changes in section as compared to CT. Soil fail more easily under BT2 than CT.
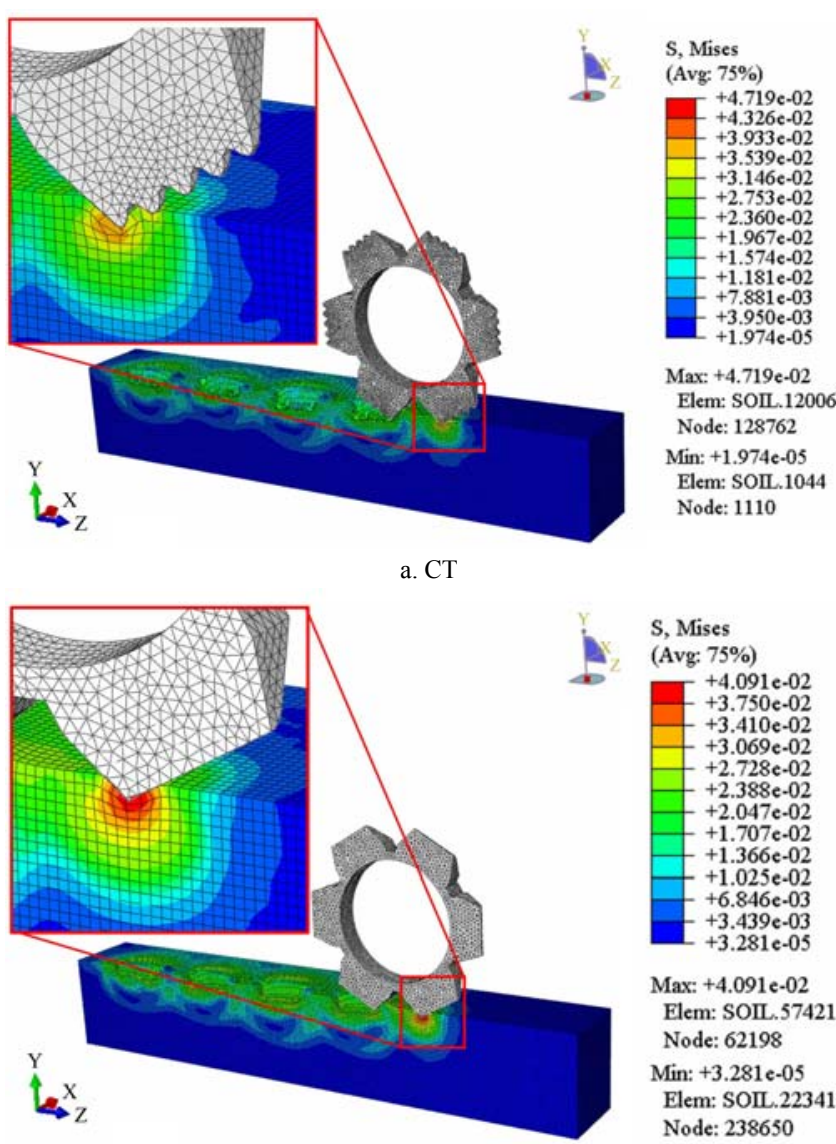

$\mathrm{S}$, Mises (Avg. 75\%)

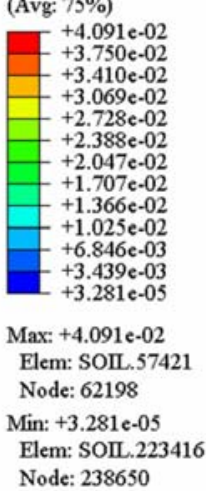

b. BT2

Figure 18 Stamping phase $(0.988 \mathrm{~s})$ 


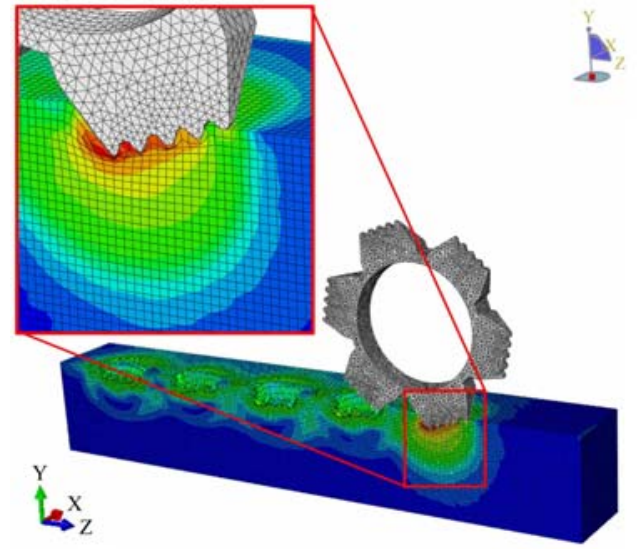

$\mathrm{S}$, Mises

(Avg: 75\%)

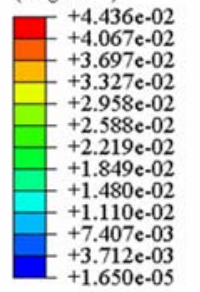

Max: $+4.436 \mathrm{e}-02$ Elem: SOIL. 55333 Node: 59978

Min: $+1.650 \mathrm{e}-05$

Elem: SOIL.183744 Node: 196470

a. CT

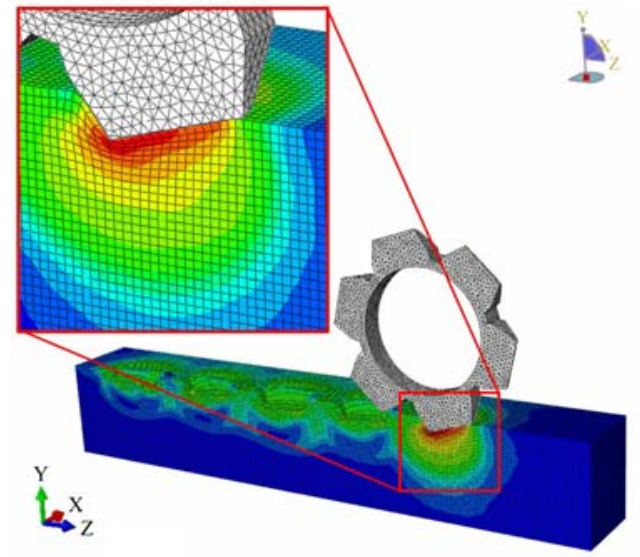

$\mathrm{S}$, Mises (Avg: 75\%)

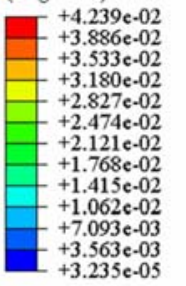

Max: $+4.239 \mathrm{e}-02$ Elem: SOIL.56378 Node: 61053 Min: $+3.235 \mathrm{e}-05$ Elem: SOIL. 223416 Node: 238650

b. BT2

Figure 19 Pressing phase (1.118 s)

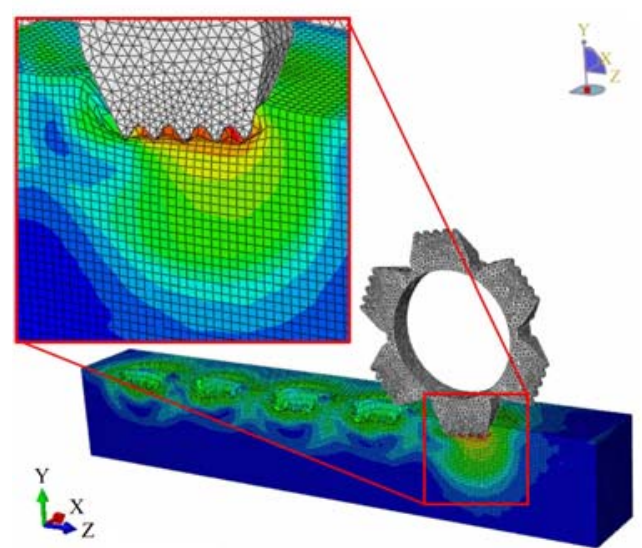

a. CT

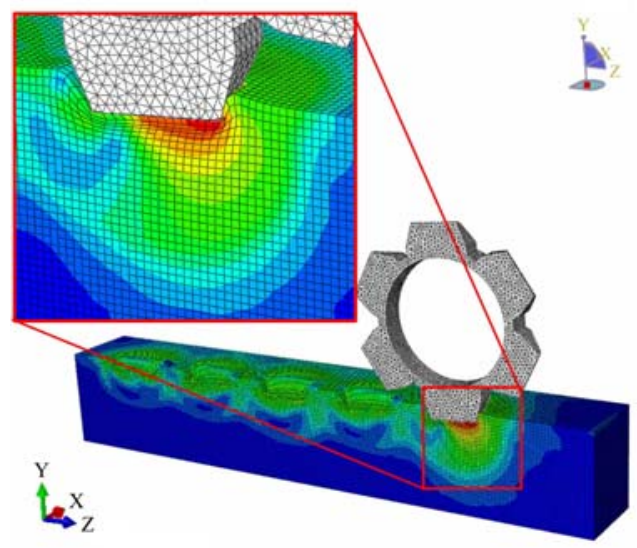

$\mathrm{S}$, Mises

(Avg: 75\%)

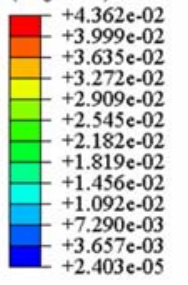

Max: $+4.362 \mathrm{e}-02$ Elem: SOIL. 42805 Node: 46621 Min: $+2.403 \mathrm{e}-05$ Elem: SOIL. 223416 Node: 238650
Figure 20 Compacting phase (1.196 s)

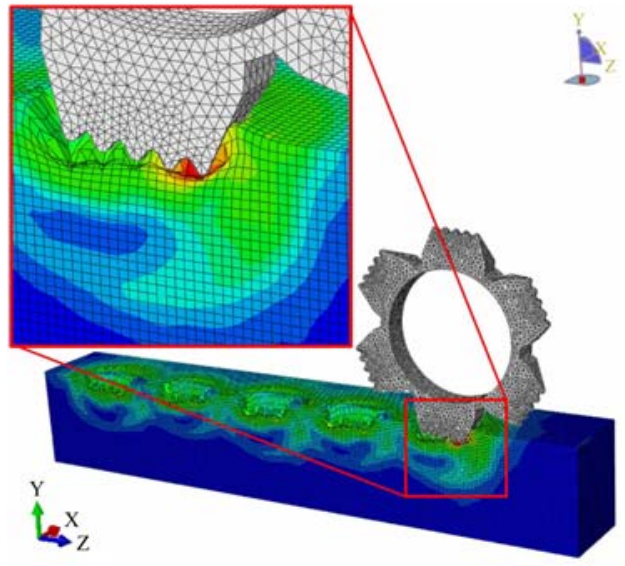

S, Mises

Avg: 75\%)

T $+4.304 \mathrm{e}-02$ $+3.946 \mathrm{e}-02$ $+3.229 \mathrm{e}-02$ $+3.229 \mathrm{e}-02$ $+2.512 \mathrm{e}-02$ $+2.153 \mathrm{e}-02$ $+1.794 \mathrm{e}-02$ $+1.436 \mathrm{e}-02$ $+1.077 \mathrm{e}-02$ $+7.188 \mathrm{e}-03$ $+3.603 \mathrm{e}-03$ $+1.762 \mathrm{e}-05$

Max: $+4.304 \mathrm{e}-02$ Elem: SOIL.40718 Node: 44403

Min: $+1.762 \mathrm{e}-05$ Elem: SOIL. 223416 Node: 238650

a. CT

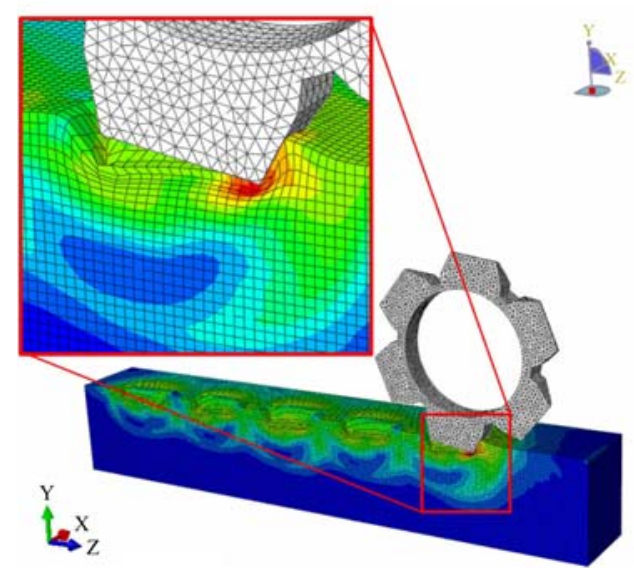

$\mathrm{S}$, Mises (Avg: 75\%)

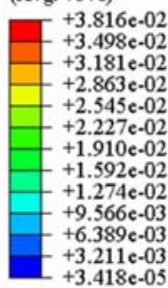

Max: $+3.816 \mathrm{c}-02$ Elem: SOIL.41761 Node: 45548

Min: +3.418e-05 Elem: SOIL.223415 Node: 238649

b. BT2

Figure 21 Rolling phase (1.248 s)

Level of concentrated stress can be evaluated by stress concentration factor, which is the ratio of the highest stress to a reference stress. In this study, the same load was applied to the toothed wheel, and toothed wheel share similar weight. Hence, reference stress in soil caused by different toothed wheel was similar. By comparing highest stress on soil and toothed wheel interface, stress concentration factor can be evaluated indirectly. Using the highest stress value which obtained in Abaqus at four working phase of toothed wheel (Figure 22), as compared to CT, the maximum stress values of BT2 increased from $4.719 \times 10^{-2}$, $4.436 \times 10^{-2}, 4.456 \times 10^{-2}$ and $4.304 \times 10^{-2} \mathrm{MPa}$, to $4.091 \times 10^{-2}$, $4.239 \times 10^{-2}, 4.362 \times 10^{-2}$ and $3.816 \times 10^{-2} \mathrm{MPa}$ respectively, the increment ratios were $15.35 \%, 4.65 \%, 2.15 \%$ and $12.79 \%$,

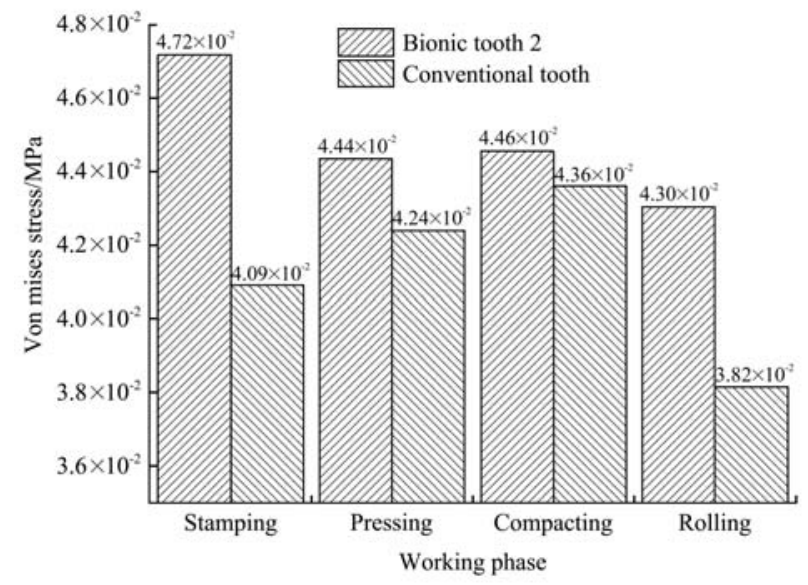

Figure 22 Maximum stress of BT2 and CT at different working phase 
correspondingly. The maximum value is on the soil element near the serrated structure where the stress concentration occurred. As mentioned before, a focus point of stress in soil is highly possible to be its point of failure, soil under the serrated structure of BT2 subjected to more stress concentration, thus unable to resist the highly concentrated stress, fail more quickly.

\section{Conclusions}

Inspired by the convergent evolution, it was found that highly efficient soil burrowing animals have geometrical analogous serrated structures on their digging claws. The analogous serrated structures of soil burrowing animals were studied, and their essence and commonality were abstracted. To reduce the forward resistance of toothed wheel and increase its soil imprinting efficiency, the biological principle of convergent evolution was applied for the novel design of bionic toothed wheel. The effects of a toothed wheel with one type of conventional tooth (CT) and three types of bionic tooth (BT1, BT2, and BT3) at three vertical loads $(250 \mathrm{~N}, 300 \mathrm{~N}$ and $350 \mathrm{~N})$ on the forward resistance and micro-basin indexes were investigated. This study recommends the use of BT2 for soil imprinting. This recommendation is according to the following evidences:

(1) Taking forward resistance as the evaluating index, forward resistance increased as implemented load increased. When operating at minor load, the forward resistance between the conventional tooth and bionic tooth were subtle, while operating at higher load, toothed wheel with BT2 showed lower forward resistance.

(2) Using depth and volume of micro-basin as the evaluating indexes, results showed that both depth and volume of micro-basin increased with the implemented load. Meanwhile, toothed wheel mounted with BT2 be able to create micro-basin with both increased depth and more volume.

(3) Compared with the toothed wheel mounted with CT, BT2 can reduce required draft force up to $6.52 \%$, increase the depth of prepared micro-basin up to $13.25 \%$, and expand the volume of prepared micro-basin up to $37.59 \%$.

(4) Toothed wheel mounted with the BT2 obtained a balance between surface area and volume. On the cutting edge, BT2 had lower surface area and volume hence when BT2 is interacting with soil, it had lower adhesion force and penetrating resistance. Moreover, main body volume of BT2 was not reduced, hence the volume of micro-basin was not limited evidently.

(5) The geometry of serrated structure has the ability to maximum stress concentrations in soil, thus increased the tendency of soil material to fail. The sharp corners at the serrated structure of BT2 induced geometric discontinuities in the soil; these discontinuities cause sudden increases in the stress at points near the stress raisers, has resulted in a localized increase in stress, such stress concentrating within the soil causing it more accessible to fail. As compared to CT, the BT2 increment ratios of maximum stress value were $15.35 \%, 4.65 \%, 2.15 \%$ and $12.79 \%$, respectively.

The hypothesis is verified that special serrated structures have the potential of reducing penetrating resistance from soil and enhancing operating efficiency for soil engaging component. Toothed wheel mounted with BT2 required less draft force for operating as compared with the conventional toothed wheel, meanwhile prepared micro-basin with increased depth and larger water harvesting volume. Hence, the BT2 would be the preferred option when undertaking soil imprinting. In addition to the above considerations, the recommended bionic serrated structures would be convenient to manufacture locally by village level artisans, potentially increasing their availability and reducing cost. Besides, the serrated structure is advantageous for the design of new soil-engaging implements adapted to each type of soil for working quality enhancement and forward resistance reduction.

\section{Acknowledgements}

Thank for the financial support for this research project by the National Natural Science Foundation of China for Young Scholars (Grant No. 51605210), by Scientific Research Project of Yunnan Provincial Education Department (Grant No. 2018Y018).

\section{[References]}

[1] Boers T M, Ben-Asher J. A review of rainwater harvesting. Agricultural Water Management, 1982; 5(2): 145-158.

[2] Salem HM, Valero C, Muñoz M Á, Gil-Rodríguez M, Barreiro P. Effect of reservoir tillage on rainwater harvesting and soil erosion control under a developed rainfall simulator. Catena, 2014; 113: 353-362.

[3] Brhane G, Wortmann C S, Mamo M, Gebrekidan H, Belay A. Micro-basin tillage for grain sorghum production in semiarid areas of Northern Ethiopia. Agronomy Journal, 2006; 98(1): 124-128.

[4] Zhao L, Hou R, Wu F. Rainwater harvesting capacity of soils subjected to reservoir tillage during rainfall on the Loess Plateau of China. Agricultural Water Management, 2019; 217: 193-200.

[5] Barron J, Okwach G. Run-off water harvesting for dry spell mitigation in maize (Zea mays L.): results from on-farm research in semi-arid Kenya. Agricultural Water Management, 2005; 74(1): 1-21.

[6] Fleskens L, Stroosnijder L, Ouessar M, De Graaff J. Evaluation of the on-site impact of water harvesting in southern Tunisia. Journal of Arid Environments, 2005; 62(4): 613-630.

[7] Oweis T, Hachum A. Water harvesting and supplemental irrigation for improved water productivity of dry farming systems in West Asia and North Africa. Agricultural Water Management, 2006; 80(1-3): 57-73.

[8] Silva L L. Are basin and reservoir tillage effective techniques to reduce runoff under sprinkler irrigation in Mediterranean conditions? Agricultural Water Management, 2017; 191: 50-56.

[9] Ward K, Carr C. Soil conditioning device. US, Patent WO 2,010,078,327. 2010.

[10] Patrick C, Kechavarzi C, James I T, O'Dogherty M, Godwin R J. Developing reservoir tillage technology for semi-arid environments. Soil Use and Management, 2007; 23(2): 185-191.

[11] Tong J, Moayad B Z, Ren L Q, Chen B C. Biomimetics in soft terrain machines: a review. International Agricultural Engineering Journal, 2004; 14: 71-86.

[12] Khan M A, Qaisrani R, Li J Q. The techniques of reducing adhesion and scouring soil by bionic-review of literature. Advances in Natural Science, 2010; 3(2): 41-50.

[13] Zhao J L, Huang D Y, Jia H L, Zhuang J, Guo M Z. Analysis and experiment on cutting performances of high-stubble maize stalks. Int $\mathrm{J}$ Agric \& Biol Eng, 2017; 10(1): 40-52.

[14] Zhang F, Zheng L M, Wang W, Wang Y F, Wang J J. Development of agricultural bionic mechanisms: Investigation of the effects of joint angle and pressure on the stability of goats moving on sloping lands. Int $\mathrm{J}$ Agric \& Biol Eng, 2018; 11(3): 35-41.

[15] Wang W J, Wang W P, Jia H L, Zhuang J, Wang Q. Effects of seed furrow liquid spraying device on sowing quality and seedling growth of maize. Int J Agric \& Biol Eng, 2019; 12(2): 68-74.

[16] Jia H L, Guo M Z, Zhao J L, Huang D Y, Zhuang J, Qi J T. Design and test of bionic wide-ridge soybean tilling-sowing machine. Int J Agric \& Biol Eng, 2019; 12(1): 42-51.

[17] Zhang Z, Wang X, Tong J, Stephen C. Innovative design and performance evaluation of bionic imprinting toothed wheel. Applied Bionics and Biomechanics, 2018; 2018: 11 .

[18] Li M, Yang Y, Guo L, Chen D, Sun H, Tong J. Design and Analysis of Bionic Cutting Blades Using Finite Element Method. Applied Bionics and Biomechanics, 2015; 2015: 7.

[19] Jia H, Li C, Zhang Z, Wang G. Design of bionic saw blade for corn stalk cutting. Journal of Bionic Engineering, 2013; 10(4): 497-505.

[20] Liu Z, Zhang Z, Ritchie R O. On the Materials Science of Nature's Arms Race. Advanced Materials, 2018; 30(32): 1705220. 
[21] Arbuckle K, Bennett C M, Speed M P. A simple measure of the strength of convergent evolution. Methods in Ecology and Evolution, 2014; 5(7): 685-693.

[22] Bomphrey R J, Godoy-Diana R. Insect and insect-inspired aerodynamics: unsteadiness, structural mechanics and flight control. Current Opinion in Insect Science, 2018; 30: 26-32.

[23] Martín-Durán J M, Pang K, Børve A, Lê H S, Furu A, Cannon J T, et al. Convergent evolution of bilaterian nerve cords. Nature, 2017; 553: 45.

[24] Ritzmann R E, Quinn R D, Fischer M S. Convergent evolution and locomotion through complex terrain by insects, vertebrates and robots. Arthropod Structure \& Development, 2004; 33(3): 361-79.

[25] Morris S C. Life's solution: inevitable humans in a lonely universe. Cambridge University Press, 2003.

[26] McGhee G R. Convergent evolution: limited forms most beautiful. MIT Press, 2011.

[27] Foote A D, Liu Y, Thomas G W C, Vinař T, Alföldi J, Deng J, et al. Convergent evolution of the genomes of marine mammals. Nature Genetics, 2015; 47: 272.

[28] Ji W F. Biomimetic blades for soil-rototilling and stubble-breaking. Doctoral thesis, Jilin University, 2010. (in Chinese)

[29] Gao H. Characteristic, function, mechanics and bionic analysis of oriental mole cricket (Gryllotalpa orientalis Burmeister). Doctoral dissertation. Changchun: Jilin University, June, 2009; 205p. (in Chinese)

[30] Ren L Q, Xu X B, Chen B C, Cui X X, Wang Y M, Zhang B L, et al. Initial research on claw shapes of the typical soil animals. Transactions of the CSAM, 1990; 21(2): 44-49. (in Chinese)

[31] Tong J, Sun J, Chen D, Zhang S. Geometrical features and wettability of dung beetles and potential biomimetic engineering applications in tillage implements. Soil and Tillage Research, 2005; 80(1-2): 1-12.

[32] Barnard P C. Order orthoptera: The grasshoppers, crickets and bush-crickets. The Royal Entomological Society Book of British Insects: Wiley-Blackwell; 2011; pp.57-63.

[33] Zhang Y, Zhou C H, Ren L Q. Biology Coupling Characteristics of Mole Crickets' Soil-Engaging Components. Journal of Bionic Engineering, 2008; 5(Supp): 164-171.

[34] Zhang Y, Huang H, Liu X, Ren L. Kinematics of terrestrial locomotion in mole cricket gryllotalpa orientalis. Journal of Bionic Engineering, 2011; 8(2): 151-157.

[35] Bailey D L, Held D W, Kalra A, Twarakavi N, Arriaga F. Biopores from mole crickets (Scapteriscus spp.) increase soil hydraulic conductivity and infiltration rates. Applied Soil Ecology, 2015; 94: 7-14.

[36] Zhang Z, Tong J, Chen D, Zhang L, Dong W, Ma Y, et al. Bionically inspired serrated structure for improving efficiency of micro-topography preparation. International Agricultural Engineering Journal, 2015; 24(4): 11-23.

[37] Tong J, Moayad B Z, Ma Y H, Sun J Y, Chen D H, Jia H L, et al. Effects of Biomimetic Surface Designs on Furrow Opener Performance. Journal of Bionic Engineering, 2009; 6(3): 280-289.

[38] Bentaher H, Ibrahmi A, Hamza E, Hbaieb M, Kantchev G, Maalej A, et al Finite element simulation of moldboard-soil interaction. Soil and Tillage Research, 2013; 134: 11-16.

[39] Abo-Elnor M, Hamilton R, Boyle J T. 3D Dynamic analysis of soil-tool interaction using the finite element method. Journal of Terramechanics, 2003; 40(1): 51-62.

[40] Abo-Elnor M, Hamilton R, Boyle J T. Simulation of soil-blade interaction for sandy soil using advanced $3 \mathrm{D}$ finite element analysis. Soil and Tillage Research, 2004; 75(1): 61-73.

[41] Tong J, Zhang Z, Chen D, Zhang Q, Ma Y. Three-dimensional dynamic finite element analysis of interaction between toothed wheel and soil. Transactions of the CSAE, 2014; 30(10): 48-58.(in Chinese)

[42] Ren L Q, Tong J, Li J Q, Chen B C. Soil adhesion and biomimetics of soil-engaging components: a review. Journal of Agricultural Engineering Research, 2001; 79(3): 239-263.

[43] Goshtasb A, Fielke J, Desbiolles J, editors. A review of soil/tool adhesion principles and approaches to reducing limitations of disc seeders. Agricultural Technologies in a Changing Climate: The 2009 CIGR International Symposium of the Australian Society for Engineering in Agriculture, 2009.

[44] Keller T, Berli M, Ruiz S, Lamandé M, Arvidsson J, Schjønning P, et al. Transmission of vertical soil stress under agricultural tyres: Comparing measurements with simulations. Soil and Tillage Research, 2014; 140: $106-117$.

[45] Keller T, Arvidsson J. A model for prediction of vertical stress distribution near the soil surface below rubber-tracked undercarriage systems fitted on agricultural vehicles. Soil and Tillage Research, 2016; 155: 116-123.

[46] Pilkey W D, Pilkey D F. Peterson's stress concentration factors. John Wiley \& Sons, 2008. 